\title{
Household Valuation of Curbside Recycling
}

\author{
David M. Aadland \\ Department of Economics \\ Utah State University \\ 3530 Old Main Hill \\ Logan, UT 84322-3530 \\ aadland@b202.usu.edu \\ and \\ Arthur J. Caplan \\ Department of Economics \\ Weber State University \\ College of Business and Economics \\ Ogden, UT 84408 \\ acaplan@weber.edu \\ December 1998 \\ Revised May 1999
}

\begin{abstract}
This paper looks at the willingness to pay for and participate in a curbside recycling program based on a survey of 401 residents in Ogden, Utah. Modifying the Cameron and James (1987) econometric model to fit ordered-interval data, we estimate that the mean willingness to pay for curbside recycling is $\$ 2.05$ per month, and that $72 \%$ of the residents would willingly participate in such a program. Furthermore, females, young people, college-educated, those currently recycling without monetary reward, those regarding recycling as beneficial to the community and nation, and those with relatively high incomes are willing to pay the most for curbside recycling.
\end{abstract}

JEL Classification: C35, D12

*The authors would like to thank the seminar participants at the department of economics at Utah State University, John B. Goddard School of Business and Economics at Weber State University, and the Utah Academy of Sciences for their helpful comments. 


\section{Introduction}

An issue of concern for many communities continues to be the alarming increase in both the volume of and disposal costs for municipal solid waste. ${ }^{1}$ These twin problems have induced county and city officials to examine waste-reduction alternatives such as recycling and composting. However, because these alternatives are commonly viewed as major departures from the status quo, officials have been cautious about implementing them. In many cases, exhaustive studies and surveys have been used to identify the most appropriate alternative. ${ }^{2}$ For example, in the early 1990's the cities of Tempe, Arizona and San Diego, California surveyed their residents' willingness to participate in and to pay for curbside recycling programs. San Diego performed follow-up surveys in those neighborhoods that subsequently piloted curbside programs. In other cases, such as in the states of Washington and Oregon, state-mandated reduction goals expedited the implementation process, thus obviating the need for such valuation surveys.

Lacking state-mandated goals, the city of Ogden, Utah has fallen into the category of exhaustive studying. ${ }^{3}$ For instance, in July of 1996, as the closure date approached for its nearest waste disposal facility, the Weber County Landfill, anxious county officials commissioned a study of its waste management system. ${ }^{4}$ It was no surprise that the study called for a host of waste-reduction and recycling initiatives (SCS Engineers, 1996). In early 1997, Ogden City’s Public Works Department began developing recycling options for the city council's consideration. ${ }^{5}$ To complement these efforts, residents' willingness to pay for and participate in a variety of curbside recycling programs were surveyed (Dan Jones and Associates, 1997).

This paper provides an analysis of the survey data. A narrow goal of our study is to 
discover what determines the value Ogden residents place on curbside recycling. Our broader goal is to aid other communities in making efficient, well-informed decisions regarding solidwaste management. In doing so, we introduce a modified approach for analyzing orderedinterval willingness-to-pay data which is not based on the (randomized) referendum or the openended approaches. The ordered-interval format, whereby respondents are presented with a series of intervals and asked to place themselves in one of the intervals, is reflective of how cities have traditionally elicited valuation information from their residents. Considering both the relative lack of academic studies on the value of curbside recycling and the wealth of survey data that we suspect exists around the country, we feel this may be a promising line of research. ${ }^{6}$

Contingent valuation $(\mathrm{CV})$ analysis has received much attention in the economics literature. This attention stems from the dual facts that some type of direct valuation of nonmarketed commodities is often necessary, and yet it is difficult to design CV surveys such that truthful revelation of preferences is a dominant strategy. The literature has consequently diverged along two strands - one critical of CV studies and the other less so. The critical literature is encapsulated in Diamond and Hausman (1994). Their argument is, on the surface, a simple one: CV responses are inconsistent with economic theory, thus CV surveys do not measure the preferences for non-marketed goods that they attempt to. As the authors implicitly acknowledge, however, this argument is premised on the assumption that the goods in question primarily deliver non-use value, such as the protection of migratory waterfowl, rather than use value, such as curbside recycling. In other words, there may be a spectrum of goods for which CV surveys more closely measure preferences; in particular goods such as curbside recycling, which resemble private goods that respondents have some prior experience paying for. ${ }^{7}$ 
The less critical strand of the literature includes studies that measure the degree of unreliability and invalidity inherent in the CV method, as well as those which apply the method to non-marketed goods. ${ }^{8}$ An attempt at synthesizing this literature into a set of survey guidelines was recently undertaken by a panel of distinguished economists, convened by the National Oceanic and Atmospheric Administration (Arrow et al., 1993). We appeal to these guidelines in the next section in order to highlight both the strengths and weaknesses of the instrument used in the Ogden survey. ${ }^{9}$

Using a recursive simultaneous model that both links willingness to pay for and participate in curbside recycling and extends to ordered-interval data the estimation technique introduced by Cameron and James (1987), we find that the mean willingness to pay for curbside recycling is $\$ 2.05$ per month, and that $72 \%$ of the residents would willingly participate in such a program. Furthermore, females, young people, college-educated, those currently recycling goods without monetary reward, those regarding recycling as beneficial to the community and nation, and those with moderately high incomes are willing to pay the most for curbside recycling. The survey instrument used for this study is discussed in the next section. Section III presents a simple theoretical framework for the ensuing empirical analysis of our data. Section IV describes the estimation technique and discusses the results of the empirical analysis. Sections V presents a summary of our findings and a discussion regarding the implementation of a curbside recycling program.

\section{Survey Instrument and Data}

The data used in this paper consists of the telephone responses of 401 residents to 85 
questions regarding various recycling programs. The survey was administered between July $29^{\text {th }}$ and August $9^{\text {th }}$ of 1997 by Dan Jones \& Associates, a professional research firm located in Salt Lake City, Utah. The variables used in this study, including the corresponding questions posed to the respondents, are described in Table 1. Summary statistics are provided in Table 2.

\section{[Insert Tables 1 and 2 here]}

It is instructive to compare our survey instrument with the guidelines for CV analysis set forth in Arrow, et al. (1993). As mentioned above, curbside recycling resembles a private good for which respondents have some prior experience paying, rather than a public good which conveys primarily non-use value. Thus, major problems generally associated with the $\mathrm{CV}$ method are diminished in our survey by virtue of the good in question. For example, the fact that respondents were asked to value $a$ curbside program, rather than to choose between a list of possible programs, eliminates what Arrow et al. label as "inconsistency with rational choice" and "implausibility of responses." Similarly, by virtue of the fact that respondents have prior experience paying for a similar good (e.g. garbage collection), the problems of "absence of a meaningful budget constraint," "information [im]provision," and "warm glow effects" are greatly minimized. ${ }^{10}$ Further, because a single curbside recycling program is presented in the survey, with no consideration of how the program might evolve over time, both the problems of "embedding" and "time dimension of ...use [gain]" are avoided.

Our survey meets the great majority of the Arrow et al. guidelines. ${ }^{11}$ For instance, by eliciting willingness to pay rather than willingness to accept, and by phrasing the willingness-topay question in a conservative interval rather than open-ended format, we reduce the chance of overestimating the value of curbside recycling, ceteris paribus. ${ }^{12}$ Further, we reduce biases 
associated with the lack of a program description because the survey opens with a series of questions concerning the respondents' current garbage collection service, and then briefly distinguishes between curbside and centralized collection programs. The fact that this distinction is made also reduces bias associated with not providing the respondents' with an adequate reminder of substitute goods for curbside recycling. Item non-response, which is accounted for by including a "don't know" option in all questions, is also minimal in the survey. In general, this option was chosen by only $0 \%$ to $3 \%$ of the respondents for any given question. ${ }^{13}$

As it turns out, our survey deviates from the Arrow et al. guidelines in one main respect — our willingness-to-pay question is elicited in an ordered-interval rather than randomized-bid format. As we show below, a willingness-to-pay model based on ordered-interval data can be analyzed similarly to one based on a randomized bid. Further, we feel that the existence of similar survey data for other cities — data which contains useful information about the management of solid waste - accentuates, rather than diminishes, the importance of the ensuing analysis.

\section{Theoretical Framework}

We assume that the $i^{\text {th }}$ individual makes a joint decision regarding her maximum willingness to pay $\left(\mathrm{PAY}_{\mathrm{i}}^{*}\right)$ for and willingness to participate $\left(\mathrm{PAR}_{\mathrm{i}}^{*}\right)$ in a curbside recycling program which presently does not exist. ${ }^{14}$ Similar to Hopper and Nielson (1991), Lake, et al. (1996), and Morris and Holthausen (1994), we assume that a loosely-defined notion of altruism motivates a typical household's demand for curbside recycling. In turn, a household's altruistic behavior is reflective not only of its concern for the environment, but also of the existence, 
option, and amenity values it ascribes to the act of recycling. Unlike Fullerton and Kinnaman (1996) and Hong, et al. (1993), the possibility of paying less for waste disposal service due to the implementation of a unit-pricing scheme is not a factor in this study which influences the household's valuation of curbside recycling. This is because unit pricing was not an issue explored by the Ogden survey, and thus households were not encouraged to consider the effects that such a scheme might have on their monthly disposal costs.

The simultaneity of the household's PAY* / PAR ${ }^{*}$ decision reflects the fact that any fee charged for recycling must be less than or equal to the individual's $\mathrm{PAY}_{\mathrm{i}}^{*}$ before she will participate. We assume $\mathrm{PAY}_{\mathrm{i}}^{*}$ is represented as

$$
\mathrm{PAY}_{\mathrm{i}}^{*}=\mathbf{X}_{\mathrm{i}}^{\prime} \boldsymbol{\beta}+\varepsilon_{\mathrm{i}}
$$

where $\varepsilon_{\mathrm{i}}$ is an i.i.d. error term with variance $\sigma_{\varepsilon}^{2}, \mathbf{X}_{\mathrm{i}}$ is a $\left(\mathrm{k}_{1} \times 1\right)$ vector of exogenous household attributes (i.e., demographic characteristics, attitudes toward recycling, travel costs to drop-off sites, sorting and storage costs, etc.), and $\beta$ is a $\left(\mathrm{k}_{1} \times 1\right)$ vector of unknown parameters. ${ }^{15}$

The willingness of an individual to participate in a curbside recycling program is based on the difference between $\mathrm{PAY}_{\mathrm{i}}^{*}$ and the expected costs of the program. In other words, $\mathrm{PAR}_{\mathrm{i}}^{*}=\delta\left(\mathrm{PAY}_{\mathrm{i}}^{*}-\mathrm{E}_{\mathrm{i}}(\mathrm{FEE})\right)$, where $\delta>0$ is an unknown parameter and $\mathrm{E}_{\mathrm{i}}(\mathrm{FEE})$ is individual $i$ 's expectation of the fee (i.e. monthly increment to her garbage collection bill) that she will pay for curbside recycling. ${ }^{16}$ Thus, $\mathrm{PAR}_{\mathrm{i}}^{*}$ may be represented as

$$
\operatorname{PAR}_{\mathrm{i}}^{*}=\mathbf{Z}_{\mathrm{i}}^{\prime} \gamma+\mu_{\mathrm{i}}
$$

where $\mu_{\mathrm{i}}$ is an i.i.d. error term with variance $\sigma_{\mu}^{2}$ and which is possibly co-variant with $\varepsilon_{\mathrm{i}}$, 
$\mathbf{Z}_{\mathrm{i}}=\left(\mathrm{PAY}_{\mathrm{i}}^{*}, \mathbf{W}_{\mathrm{i}}\right)$ is a $\left(\mathrm{k}_{2} \times 1\right)$ vector of explanatory variables possibly overlapping with $\mathbf{X}_{\mathrm{i}}$, and $\boldsymbol{\gamma}$ is a $\left(\mathrm{k}_{2} \times 1\right)$ vector of unknown parameters. The vector $\mathbf{W}_{\mathrm{i}}$ represents those variables which are included in the deterministic portion of $\mathrm{E}_{\mathrm{i}}(\mathrm{FEE})$ and include items such as the individual's estimate of the average monthly trash collection fee in Utah, whether the individual currently recycles, and several demographic variables. The specific variables comprising $\mathbf{X}_{\mathrm{i}}$ and $\mathbf{Z}_{\mathrm{i}}$ in this study are discussed in further detail in the next section.

Equations (1) and (2) represent a qualitative response system because the continuous variables $\mathrm{PAY}_{\mathrm{i}}^{*}$ and $\mathrm{PAR}_{\mathrm{i}}^{*}$ are observed as discrete choices within specified intervals of willingness to pay and participate. The discrete counterparts to $\mathrm{PAY}_{\mathrm{i}}^{*}$ and $\mathrm{PAR}_{\mathrm{i}}^{*}$, represented by $\mathrm{PAY}_{\mathrm{i}}$ and $\mathrm{PAR}_{\mathrm{i}}$, are defined as

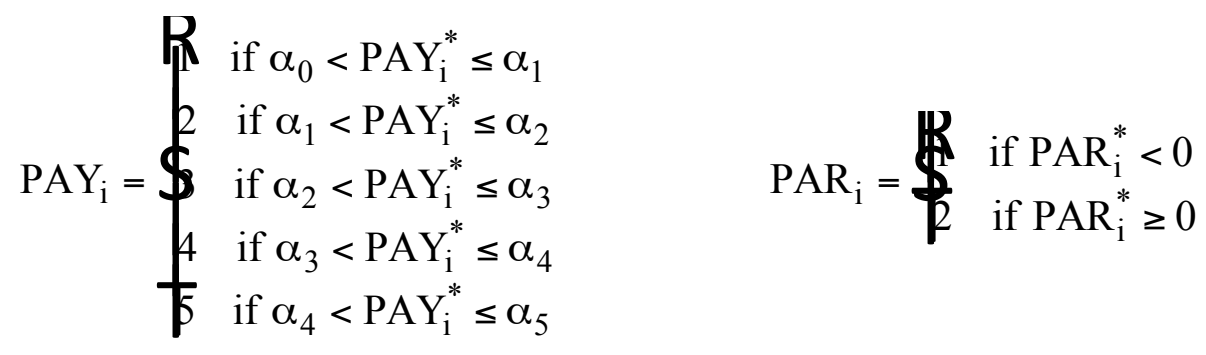

where $\alpha_{0}=-\infty, \alpha_{1}=\$ 1.00, \alpha_{2}=\$ 1.50, \alpha_{3}=\$ 2.00, \alpha_{4}=\$ 2.50$, and $\alpha_{5}=+\infty$.

\section{Econometric Analysis}

\section{Estimation Procedure}

The theoretical model given by (1) and (2) above depicts a recursive simultaneous system in which the $i^{\text {th }}$ individual makes a joint decision regarding her willingness to pay for and willingness to participate in a curbside recycling program. The system is simultaneous because 
the latent variables $\mathrm{PAY}_{\mathrm{i}}^{*}$ and $\mathrm{PAR}_{\mathrm{i}}^{*}$ are jointly determined by the model, and it is recursive in the sense that $\mathrm{PAR}_{\mathrm{i}}^{*}$ depends on $\mathrm{PAY}_{\mathrm{i}}^{*}$ but not vice versa. ${ }^{17}$ While in theory the system could be estimated by full-information maximum likelihood, the recursive nature of the system lends itself to a less-computationally intense two-stage estimation procedure which produces consistent estimates of the parameters.

The two-stage estimation procedure is as follows. ${ }^{18}$ In the first stage, we estimate the parameter vector $\boldsymbol{\theta}_{1}=\left\{\frac{\alpha_{0}}{\sigma_{\varepsilon}}, \ldots, \frac{\alpha_{5}}{\sigma_{\varepsilon}}, \frac{\beta}{\sigma_{\varepsilon}}\right\}$ by maximizing the log-likelihood function

$$
\ln \mathrm{L}\left(\boldsymbol{\theta}_{1}\right)=\sum_{\mathrm{i}=1}^{\mathrm{n}} \sum_{\mathrm{j}=1}^{5} \mathrm{w}_{\mathrm{ij}} \ln \left(\mathrm{P}_{\mathrm{ij}}\right)
$$

where there are 5 choices for the dependent variable, $\mathrm{w}_{\mathrm{ij}}$ equals one if the $i^{\text {th }}$ individual makes the $j^{\text {th }}$ choice and zero otherwise, $\mathrm{P}_{\mathrm{ij}}$ gives the probability that the $i^{\text {th }}$ individual makes the $j^{\text {th }}$ choice:

$$
P_{i j}=\operatorname{Prob}\left(P A Y_{i}=j\right)=F\left(\frac{1}{\sigma_{\varepsilon}}\left(-X_{i}^{\prime} \beta+\alpha_{j}\right)\right)-F\left(\frac{1}{\sigma_{\varepsilon}}\left(-X_{i}^{\prime} \beta+\alpha_{j-1}\right)\right)
$$

and $\mathrm{F}$ is a well-defined cumulative density function (CDF). For most distributions, maximization of (3) is a nonlinear estimation problem, and therefore, an estimate of $\boldsymbol{\theta}_{1}$ is obtained by employing an iterative optimization routine such as Newton's method.

In the second stage, estimates of $\mathrm{PAY}_{\mathrm{i}}^{*}$ from (1) are substituted into (2) resulting in

$$
\operatorname{PAR}_{\mathrm{i}}^{*}=\hat{\mathbf{Z}}_{\mathrm{i}}^{\prime} \gamma+\mathrm{v}_{\mathrm{i}}
$$

where $\hat{\mathbf{Z}}_{i}=\left(\mathbf{X}_{i}^{\prime} \hat{\boldsymbol{\beta}}, \mathbf{W}_{i}\right), \hat{\boldsymbol{\beta}}$ is the ML estimate of $\boldsymbol{\beta}, v_{i}=\mu_{i}+\gamma_{1}\left(\mathbf{X}_{i}^{\prime}(\boldsymbol{\beta}-\hat{\boldsymbol{\beta}})+\varepsilon_{i}\right)$ is a composite error term with variance $\sigma_{v}^{2}$, and $\gamma_{1}$ is the first element of $\gamma$. An estimate of $\boldsymbol{\theta}_{2}=\left\{\gamma / \sigma_{v}\right\}$ is 
then produced by maximizing

$$
\ln \mathrm{L}\left(\boldsymbol{\theta}_{2}\right)=\sum_{\mathrm{i}=1}^{\mathrm{n}} \sum_{\mathrm{j}=1}^{2} \mathrm{w}_{\mathrm{ij}} \ln \left(\mathrm{P}_{\mathrm{ij}}\right)
$$

where $\mathrm{w}_{\mathrm{ij}}$ is defined as before, and $\mathrm{P}_{\mathrm{i} 1}$ and $\mathrm{P}_{\mathrm{i} 2}=1-\mathrm{P}_{\mathrm{i} 1}$ are now given by

$$
\left.\mathrm{P}_{\mathrm{i} 1}=\operatorname{Prob}\left(\operatorname{PAR}_{\mathrm{i}}=1\right)=\mathrm{F}\left(-\mathbf{Z}_{\mathrm{i}}^{\prime} \frac{\gamma}{\sigma_{v}}\right)\right)
$$

Again, maximization of (5) is a nonlinear optimization problem and can be solved using numerical optimization. As is common in linear regression analysis, we assume $\mathrm{F}$ to be the standard normal cumulative density function making the models in stages \#1 and \#2 multinomial and binomial ordered probit models, respectively. ${ }^{19}$

Before discussing our estimation results, the issue of identification must be addressed. In referendum-type willingness-to-pay questions, $\boldsymbol{\beta}$ is often identified using Cameron and James' censored probit (or logit) model (which is tantamount to including the randomized opening bid in the $\mathbf{X}_{\mathrm{i}}$ vector; see Cameron and James (1987)). However, as discussed in section II, the willingness-to-pay question in this survey was presented in an ordered-interval format and thus a different method for achieving identification is necessary.

Begin by noticing that in the absence of any further restrictions, the parameters in the numerators and denominators of $\boldsymbol{\theta}_{1}$ and $\boldsymbol{\theta}_{2}$ are not identified. It is apparent from (4) and (6) that we would only be able to estimate the ratios $\beta / \sigma_{\varepsilon}, \alpha_{j} / \sigma_{\varepsilon}$, and $\gamma / \sigma_{v}$ and, as a result, would be unable to generate mean willingness-to-pay estimates, $\mathrm{E}\left(\mathrm{PAY}^{*} \mid \mathbf{X}\right)=\overline{\mathbf{X}}^{\prime} \hat{\boldsymbol{\beta}}$, where $\overline{\mathbf{X}}$ indicates the average across individuals. ${ }^{20}$ However, since the interval cutoff values (i.e., $\alpha_{j}$ for $\mathrm{j}=0, \ldots, 5)$ are known with certainty in our study, we can substitute in these known cutoff values 
in order to estimate $\sigma_{\varepsilon}$ and $\beta$ directly. We make no attempt to separately identify $\gamma$ and $\sigma_{v}$. Moreover, since $\sigma_{\varepsilon}$ and $\beta$ are estimated separately, standard econometric packages automatically produce appropriate asymptotic standard errors so that tests of significance and goodness-of-fit may easily be carried out.

\section{Discussion of the Results}

Once estimates of these parameters have been obtained, we then estimate probabilities, marginal effects and goodness-of-fit measures associated with both equations (1) and (2). One advantage of the simple linear representation of (1), which allows for negative willingness to pay (as opposed to the more standard log-linear representation), is that the marginal effects on PAY ${ }_{\mathrm{i}}^{*}$ from a unit change in $\mathbf{X}_{\mathrm{i}}$ are simply given by the estimates of $\boldsymbol{\beta}$. The same, however, is not true for the willingness-to-participate equation. As mentioned above, we do not attempt to identify the individual elements in $\boldsymbol{\theta}_{2}$, and instead follow the usual normalization procedure of setting $\sigma_{v}=1$. This normalization, along with the fact that the coefficients are not the respective derivatives of the probability of participation, make the coefficients in (2) difficult to interpret; see Greene (1993, pp. 927-929). In response, we report only the marginal effects (evaluated at the means) of changes in $\mathbf{Z}_{\mathrm{i}}$ on $\mathrm{P}_{\mathrm{ij}}$.

Table 3 presents our estimation results. ${ }^{21}$ Column 2 contains the change in an individual's willingness to pay associated with a change in each of the binary explanatory variables from zero to one, all else being equal. Taken together, these explanatory variables

explain a statistically significant portion of the variation in PAY. ${ }^{22}$ In addition to the equation's 
overall significance, several individual variables are influential in explaining an individual's willingness to pay for curbside recycling.

$$
\text { [Insert table } 3 \text { here] }
$$

First, based on our point estimates, an individual who currently recycles items such cardboard, plastics, glass or paper for which there is no monetary gain (CPGP recycler) is willing to pay 21 cents more than a non-CPGP recycler, everything else equal, for a curbside recycling program. Whereas, an individual who recycles newspapers and aluminum for which there is monetary gain (NA recycler) is, statistically speaking, not willing to pay any more than a nonNA recycler. ${ }^{23}$ This result is intuitive, as it indicates that individuals who recycle solely out of altruistic motives are willing to pay more for curbside recycling, presumably due to a reduction in travel costs and/or increased likelihood that the curbside program will induce others to increase their recycling activities. NA recyclers, on the other hand, stand to gain little from curbside recycling because they are, all else being equal, less likely to receive any altruistic benefits or travel-cost reductions. This latter result contrasts with Lake, et al. (1996), who find that those who currently recycle are less likely to refuse any particular fee level.

Second, all remaining variables which influence willingness to pay for curbside recycling in a statistically-significant manner do so in a positive fashion. That is, all else equal, if an individual (i) feels that recycling is beneficial to the community and country, $\mathrm{s} / \mathrm{he}$ is willing to pay 41 cents more than someone who feels recycling is either somewhat, not very, or not at all beneficial; (ii) is willing to travel over two miles to a drop-off location, s/he is willing to pay an additional 19 cents; (iii) is female, she is willing to pay 37 more cents than her male counterpart; (iv) is between the ages of 18 and 34 , s/he is willing to pay 44 cents more than someone over the 
age of 55; (v) has some college training, s/he is willing to pay 15 cents more than someone with no more than a high school education; (vi) is a college or post-college graduate, $\mathrm{s} / \mathrm{he}$ is willing to pay 41 cents more than someone with no more than a high school education; and (vii) has an income between $\$ 30 \mathrm{~K}$ and $\$ 50 \mathrm{~K}$, s/he is willing to pay 23 more cents than someone with an income below $\$ 30 \mathrm{~K}^{24}$

These demographic regularities suggest revenue-maximizing strategies for local governments that would target individuals with the highest willingness to pay. For instance, if local governments promote recycling as good for the environment, say through a recyclingawareness program, then they may increase people's willingness to pay for curbside recycling. Our results also suggest that recycling-awareness programs targeting women may ultimately lead to more flexibility in the fee structure — the greater the percentage of women who participate in a new curbside recycling program the higher a permissible fee. Similarly, the more highly educated the population, the higher a permissible fee for recycling.

Tiller et al. (1997) also find that demographic variables influence a household's willingness to pay for drop-off recycling, however, in some cases their results are strikingly different than ours. For example, they find that household income positively affects a rural household's, but has no effect on a suburban household's, willingness to pay. Education negatively affects a rural household's willingness to pay when that household does not currently recycle, but has no effect on either a rural or suburban household who currently recycles. Further, Tiller et al. find that an increase in age reduces the willingness to pay for rural households who currently recycle (there is no age effect for rural households who do not presently recycle or for suburban households). Lastly, they find that a suburban household's 
willingness to pay is further reduced as its belief in recycling as a means to reduce landfill waste grows stronger. Lake, et al. (1996) find that, aside from its previous recycling behavior, no other demographic variables influence a household's willingness to pay for curbside recycling.

Turning to participation, in column 3 of Table 3 we present the marginal effects (evaluated at the means) of a change in $\mathbf{Z}_{\mathrm{i}}$ on the probability of participation in a curbside recycling program. Since the marginal effects are complicated nonlinear combinations of the coefficients, we calculated $95 \%$ confidence bounds from 500 bootstrap simulations by resampling with replacement from the original data matrix (PAY,PAR,X,Z); see Davidson and MacKinnon (1993, pp 763-768). During the bootstrap simulations, we were careful to calculate a new generated regressor for each round of the simulation so that the extra uncertainty involved with estimation of $\mathrm{PAY}_{\mathrm{i}}^{*}$ would be incorporated in the final confidence bounds.

Estimation results indicate that the predominant influence on one's willingness to participate in a curbside recycling program is PAY*, although Middle Income and Young are also statistically-significant variables. ${ }^{25}$ This is confirmed by noticing that although the likelihood ratio (LR) test indicates joint significance of all the variables in $\mathbf{Z}_{\mathrm{i}}$ (the LR statistic for testing the null hypothesis that $\gamma=0$ equals 72.15 and is significant at the $1 \%$ level), when the predicted value of $\mathrm{PAY}_{\mathrm{i}}^{*}$ is excluded, the remaining variables in $\mathbf{Z}_{\mathrm{i}}$ are no longer statistically important (the LR statistic equals 16.06 , whereas the $10 \%$ critical value is 19.81 ). In other words, it appears that the single most important factor in determining whether an individual will participate in curbside recycling is his estimated willingness to pay. In particular, the marginal effects indicate that an increase in willingness to pay of, say, 10 cents leads to an impressive 7.56 
percentage point increase in the probability that one will participate in curbside recycling. ${ }^{26}$

These results are similar to Fullerton and Kinnaman (1996), who find that aside from unit pricing of non-recyclable waste no other demographic variables jointly determine a household's participation in curbside recycling (measured as pounds of recyclable material generated). Hong, et al. (1993), on the other hand, find that several demographic variables in addition to unit pricing determine the probability of participation (measured as frequency of setting out recyclables at the curb), including household size, education level of head of household, whether or not the home is owned or rented, and race. Additional support for the role of demographics in explaining participation can be found in the environmental-psychology literature. For instance, Oskamp, et al. (1991) find that a household's participation in a voluntary recycling program depend upon household income, whether or not the residence is single-family, whether or not the residence is owned, general knowledge of conservation, intrinsic motives, and whether or not friends and neighbors recycle. Hopper and Nielsen (1991) find that in addition to experimental interventions (such as informational flyers, prompting, and block leaders), personal norms and awareness of the consequences associated with not recycling affect participation (measured as frequency of setting out recyclables at the curb). Interestingly, none of the aforementioned studies on participation allow for simultaneity in the household's decision-making process. ${ }^{27}$

In addition to marginal effects, we present estimates of willingness to pay and probability of participation for the mean and median individuals. The mean values are displayed toward the bottom of Table 3. Beginning with willingness to pay, our ML estimates indicate that the mean individual is willing to pay between $\$ 0.52$ and $\$ 3.59$ extra per month for curbside recycling service, with a point estimate of $\$ 2.05$. This amount differs very little from the median 
willingness to pay, which is also approximately $\$ 2.05$, but is one to two dollars lower than the estimates obtained by Stock (1997) for curbside recycling and Tiller, et al. (1997) for drop-off. ${ }^{28}$ In Figure 1, we present the within-sample frequency distribution of point estimates for willingness to pay. The empirical distribution appears to be symmetric about the mean of $\$ 2.05$, with only six observations falling outside the $[\$ 1.00, \$ 3.00]$ interval. As for the predicted mean probability of participation we find (based on the bootstrapping procedure) that the mean probability of participation in a curbside recycling program is between 66 and 78 percent, with a point estimate of 72 percent. $^{29}$ In this case, the median point estimate is 63 percent, which indicates that the empirical distribution of probabilities is skewed toward one. Figure 2 confirms this suspicion.

Several methods have been proposed for analyzing how well qualitative-response models fit the data — within-sample prediction performance, pseudo $\mathrm{R}^{2} \mathrm{~s}$, likelihood ratio statistics, etc.; see Amemiya (1981) and Maddala (1983). Since we have already presented likelihood ratio statistics for the two models, we turn our focus to within-sample prediction performance. Tables 4 and 5 summarize the number of hits and misses in the two models, respectively, with the elements in the $(x, y)$ cell indicating how many times an individual observed in the $x^{\text {th }}$ interval was predicted to fall in the $y^{\text {th }}$ interval. For willingness to pay (equation (1)) the prediction rule assigns a hit if the estimate for $\mathrm{PAY}_{\mathrm{i}}^{*}$ falls within the interval chosen by the $i^{\text {th }}$ individual; while for willingness to participate (equation 2) the rule assigns a hit if a (non-) willing participator has a predicted probability of participation (less) greater than 0.5 . Diagonal values therefore indicate the number of correct predictions, and off-diagonal values indicate the number of incorrect predictions, with the cells farthest away from the diagonal, in some sense, representing the most 
serious prediction errors.

\section{[Insert Tables 4 and 5 here]}

Beginning with the in-sample fit of (1), Table 4 reveals that overall the model correctly predicts 29 percent of the willingness-to-pay categories. Although this percentage does not indicate an excellent fit, recall that the maximum-likelihood estimation criteria is not maximizing any goodness-of-fit measure as in the linear regression model (Greene 1993, p. 182). Furthermore, if one counts "near-misses" (i.e., predictions that miss by a single category), the model's predictive performance improves to 79 percent, with an average miss of only 22 cents. The predictive performance of the willingness-to-participate model is presented in Table 5. The total percentage of correct predictions is 73 percent, with an average distance from the cutoff for all misses equal to 0.17 . This model is a marginal improvement over the 68 percent of correct predictions given by the "naive model" where one simply predicts that all observations fall in the category with the largest observed frequency. In sum, although the willingness-to-pay and willingness-to-participate models fair about the same as their associated naive models with respect to traditional in-sample prediction, our models appear to fit the data reasonably well given that the majority of misses are "near hits".

\section{Conclusion}

The results of this study should be viewed from two perspectives — one focusing on the estimation method, the other on specific findings regarding the value of curbside waste recycling. The estimation method for randomized-bid models proposed by Cameron and James (1987) was modified and applied to survey data from Ogden, Utah, where the willingness-to-pay 
question was posed as an ordered-interval choice. The purpose of this application was to fully identify the determinants of the respondents' willingness to pay and participate in curbside recycling, and in turn, directly estimate the population mean willingness to pay and probability of participation for the entire city. On this note, we find several demographic variables which are statistically-significant determinants of willingness to pay. We also estimate that on average residents are willing to pay $\$ 2.05$ per month, and that about $72 \%$ of the residents would willingly participate in such a program.

To assist the city council in implementing a curbside recycling program, Ogden City's Public Works Department recently prepared a five-year projection of estimated costs for fullyautomated split-carts. ${ }^{30}$ The split-cart option entails one truck per street per week, which collects both co-mingled recyclable and non-recyclable solid wastes (RSW and non-RSW, respectively). The breakeven monthly fee per household assuming mandatory participation was calculated at $\$ 2.58$ for 1999 , falling to $\$ 2.22$ by 2002 due to expected efficiency gains. ${ }^{31}$ These are fees necessary to cover the added curbside-collection costs of green waste and RSW, relative to the status quo of collecting neither. ${ }^{32}$ Given these forecasts of the costs associated with implementing a curbside recycling program, we project that Ogden will breakeven only if households are charged a small additional fee for the curbside collection of green waste or are able to generate sufficient revenues through the sale of RSW.

Assuming that a community similar to Ogden - which is planning to implement a curbside recycling program in the near future - desires to set a mandatory monthly household fee for curbside service that is near the typical household's maximum willingness to pay, then our findings have a clear implication. The community's public works department should consider 
targeting its promotional advertising campaign toward residents who are male, older, lowerincome, and/or have less formal education. These individuals are, on average, not willing to pay as much for curbside recycling service. Because an individual's willingness to participate is positively related to his maximum willingness to pay, these individuals will also be less likely to willingly participate in any given curbside program. As a result, they will be more likely to resist the implementation of a given program at the outset.

The planning process followed by Ogden City's Public Works Department in its development of a cost-effective recycling program exemplifies this strategy, and more. For instance, it has solicited the help of a regional recycling association (known as the Southwest Public Recycling Association) in identifying the most appropriate recycling options for the Ogden community, and in estimating associated implementation costs. It has worked closely with the city council at each step in the process, and is presently soliciting bids for various components of the recycling options under consideration. In addition to committing itself to the curbside collection of green waste, the city council has also accepted the need for a variable-rate structure, in order to provide incentives for households to reduce their garbage volumes.

As for promoting the general idea of curbside recycling, the public works department is considering targeted advertising. It recognizes that even though the typical household may be willing to pay the full amount for curbside recycling, there will be opposition from other types of households. Changing the attitudes of these opposing households will be an important measure of the city's success in implementing a recycling program. The city has also recognized that an education program regarding the specific recycling option chosen will have to be broad based, touching every household regardless of its acceptance or rejection of the principle of recycling. 
Finally, and perhaps most significantly, the city has recognized that educating youth directly through the public school system will help ensure any recycling program's future acceptance. It is therefore considering an education program specifically targeted to its elementary and middle schools. 
Table 1. Variable Descriptions

\begin{tabular}{|c|c|c|}
\hline Variable & Survey Question & Values \\
\hline PAR & $\begin{array}{l}\text { And if Ogden City implemented a curbside recycling } \\
\text { program, how likely would by be to participate? }\end{array}$ & $\begin{array}{c}1 \text { if very likely } \\
0 \text { if somewhat, not very or } \\
\text { not at all likely }\end{array}$ \\
\hline PAY & $\begin{array}{l}\text { As you probably already know, it currently costs residents } \\
\$ 10.65 \text { per month for garbage collection. In addition, to } \\
\text { your current monthly bill, how much would you be willing } \\
\text { to pay each month for a curbside recycling program? }\end{array}$ & $\begin{array}{c}1 \text { if } \mathrm{PAY}^{*}<\$ 1.00 \\
2 \text { if } \$ 1.00<\mathrm{PAY}^{*}<\$ 1.50 \\
3 \text { if } \$ 1.50<\mathrm{PAY}^{*}<\$ 2.00 \\
4 \text { if } \$ 2.00<\mathrm{PAY}^{*}<\$ 2.50 \\
5 \text { if } \mathrm{PAY}^{*}>\$ 2.50\end{array}$ \\
\hline Collection & $\begin{array}{l}\text { On a scale of } 1 \text { to } 5 \text {, with } 1 \text { being poor and } 5 \text { meaning } \\
\text { excellent, how would you rate Ogden City's current weekly } \\
\text { trash collection program? }\end{array}$ & $\begin{array}{l}1 \text { if rating }=4 \text { or } 5 \\
0 \text { if rating }=1,2 \text { or } 3\end{array}$ \\
\hline $\begin{array}{c}\text { NA } \\
\text { Recycler }\end{array}$ & $\begin{array}{l}\text { In the past six months, have you recycled any of the } \\
\text { following: newspapers or aluminum? }\end{array}$ & $\begin{array}{l}1 \text { if recycled one or more items } \\
0 \text { otherwise }\end{array}$ \\
\hline $\begin{array}{l}\text { CPGP } \\
\text { Recycler }\end{array}$ & $\begin{array}{l}\text { In the past six months, have you recycled any of the } \\
\text { following: cardboard, plastics, glass, and paper? }\end{array}$ & $\begin{array}{l}1 \text { if recycled one or more items } \\
0 \text { otherwise }\end{array}$ \\
\hline Benefits & $\begin{array}{l}\text { In your opinion, how beneficial to the community and } \\
\text { country is recycling? }\end{array}$ & $\begin{array}{l}1 \text { if very beneficial } \\
0 \text { if somewhat, not very or not at } \\
\text { all beneficial }\end{array}$ \\
\hline Drop-off & $\begin{array}{l}\text { How willing would you be to take your recyclabes to a drop- } \\
\text { off location for recycling? }\end{array}$ & $\begin{array}{l}1 \text { if very or somewhat willing } \\
0 \text { if not very or not at all willing }\end{array}$ \\
\hline Travel & $\begin{array}{l}\text { What is the farthest location you would be willing to travel } \\
\text { to a drop-off location? }\end{array}$ & $\begin{array}{l}1 \text { if over } 2 \text { miles } \\
0 \text { if under } 2 \text { miles }\end{array}$ \\
\hline Female & Gender: & $\begin{array}{l}1 \text { if female } \\
0 \text { if male }\end{array}$ \\
\hline Young & Age Category: & $\begin{array}{c}1 \text { if } 18<\text { age }<34 \\
0 \text { if age }>34\end{array}$ \\
\hline Middle-aged & same as above & $\begin{array}{l}1 \text { if } 35<\text { age }<54 \\
0 \text { if } 35>\text { age }>54\end{array}$ \\
\hline
\end{tabular}


Table 1. Variable Descriptions (continued from previous page)

\begin{tabular}{|c|c|c|}
\hline Variable & Survey Question & Values \\
\hline Some College & What is the last level of education you completed? & $\begin{array}{l}1 \text { if some college/tech. school } \\
0 \text { otherwise }\end{array}$ \\
\hline College Grad & same as above & $\begin{array}{l}1 \text { if (post) college graduate } \\
0 \text { otherwise }\end{array}$ \\
\hline Middle Income & Approximate annual family income category & $\begin{array}{c}1 \text { if } \$ 30 \mathrm{~K}<\text { income }<\$ 50 \mathrm{~K} \\
0 \text { otherwise }\end{array}$ \\
\hline High Income & same as above & $\begin{array}{c}1 \text { if income }>\$ 50 \mathrm{~K} \\
0 \text { otherwise }\end{array}$ \\
\hline Unknown Income & same as above & $\begin{array}{l}1 \text { if income not revealed } \\
0 \text { otherwise }\end{array}$ \\
\hline Low Trash Fee & $\begin{array}{l}\text { What would you estimate to be the average monthly charge } \\
\text { per household for trash collection in Utah? }\end{array}$ & $\begin{array}{l}1 \text { if fee }<\$ 13 \\
0 \text { if Don't Know or High Fee }\end{array}$ \\
\hline High Trash Fee & same as above & $\begin{array}{l}1 \text { if fee }>\$ 13 \\
0 \text { if Don't Know or Low Fee }\end{array}$ \\
\hline
\end{tabular}


Table 2. Descriptive Statistics $(\mathrm{N}=335)$

\begin{tabular}{ccccc}
\hline \hline Variable & \multicolumn{4}{c}{ Descriptive Statistics } \\
\cline { 2 - 5 } & Mean & $\begin{array}{c}\text { Standard } \\
\text { Deviation }\end{array}$ & Minimum & Maximum \\
\hline PAR & 0.684 & 0.466 & 0 & 1 \\
PAY & 3.442 & 1.389 & 1 & 5 \\
Collection & 0.785 & 0.411 & 0 & 1 \\
NA Recycler & 0.773 & 0.419 & 0 & 1 \\
CPGP Recycler & 0.433 & 0.496 & 0 & 1 \\
Benefits & 0.749 & 0.434 & 0 & 1 \\
Drop-off & 0.699 & 0.460 & 0 & 1 \\
Travel & 0.451 & 0.498 & 0 & 1 \\
Female & 0.510 & 0.501 & 0 & 1 \\
Young & 0.361 & 0.481 & 0 & 1 \\
Middle-aged & 0.370 & 0.484 & 0 & 1 \\
Some College & 0.382 & 0.487 & 0 & 1 \\
College Grad & 0.325 & 0.469 & 0 & 1 \\
Middle Income & 0.379 & 0.486 & 0 & 1 \\
High Income & 0.236 & 0.425 & 0 & 1 \\
Unknown Income & 0.057 & 0.232 & 0 & 1 \\
Low Trash Fee & 0.254 & 0.436 & 0 & 1 \\
High Trash Fee & 0.516 & 0.501 & 0 & 1 \\
See table & & 0.45 & 0 & 1 \\
\hline
\end{tabular}

Notes: See table 1 for a detailed description of the variables. Although 401 residents were surveyed, we discarded 66 observations because these individuals failed to answer at least one of the questions. 
Table 3. Estimated Marginal Effects for Willingness to Pay and Participate

\begin{tabular}{|c|c|c|}
\hline \multirow{2}{*}{ Explanatory Variable } & \multicolumn{2}{|c|}{ Dependent Variable } \\
\hline & PAY & PAR \\
\hline Collection & $\begin{array}{c}0.060 \\
(0.116)\end{array}$ & $\begin{array}{c}0.008 \\
(-0.129)(0.180)\end{array}$ \\
\hline NA Recycler & $\begin{array}{l}-0.083 \\
(0.132)\end{array}$ & $\begin{array}{c}-0.030 \\
(-0.161)(0.140)\end{array}$ \\
\hline CPGP Recycler & $\begin{array}{c}0.208^{* *} \\
(0.110)\end{array}$ & $\begin{array}{c}-0.024 \\
(-0.111)(0.050)\end{array}$ \\
\hline Benefits & $\begin{array}{c}0.413 * * * \\
(0.112)\end{array}$ & \\
\hline Drop-off & $\begin{array}{c}0.077 \\
(0.115)\end{array}$ & \\
\hline Travel & $\begin{array}{c}0.189 * * \\
(0.100)\end{array}$ & \\
\hline Female & $\begin{array}{c}0.366^{* * * *} \\
(0.096)\end{array}$ & $\begin{array}{c}-0.060 \\
(-0.158)(0.026)\end{array}$ \\
\hline Young & $\begin{array}{c}0.436^{* * * *} \\
(0.126)\end{array}$ & $\begin{array}{c}-0.092 * * \\
(-0.164)(-0.015)\end{array}$ \\
\hline Middle-aged & $\begin{array}{c}0.234 \\
(0.128)\end{array}$ & $\begin{array}{c}-0.061 \\
(-0.144)(0.022)\end{array}$ \\
\hline Some College & $\begin{array}{l}0.151^{*} \\
(0.117)\end{array}$ & $\begin{array}{c}-0.027 \\
(-0.095)(0.040)\end{array}$ \\
\hline College Grad & $\begin{array}{c}0.413 * * * \\
(0.128)\end{array}$ & $\begin{array}{c}-0.032 \\
(-0.133)(0.043)\end{array}$ \\
\hline Middle Income & $\begin{array}{c}0.225^{* *} \\
(0.117)\end{array}$ & $\begin{array}{c}-0.069 * * \\
(-0.142)(-0.004)\end{array}$ \\
\hline High Income & $\begin{array}{c}0.048 \\
(0.139)\end{array}$ & $\begin{array}{c}0.001 \\
(-0.044)(0.047)\end{array}$ \\
\hline Unknown Income & $\begin{array}{l}-0.121 \\
(0.214)\end{array}$ & $\begin{array}{c}-0.000 \\
(-0.015)(0.019)\end{array}$ \\
\hline Low Trash Fee & & $\begin{array}{c}0.005 \\
(-0.067)(0.074)\end{array}$ \\
\hline High Trash Fee & & $\begin{array}{c}-0.001 \\
(-0.042)(0.044)\end{array}$ \\
\hline Predicted PAY & & $\begin{array}{c}0.756 * * * \\
(0.457)(1.154)\end{array}$ \\
\hline Mean PAY* & $\begin{array}{c}2.05 \\
(0.519)(3.589)\end{array}$ & \\
\hline Mean $\operatorname{Prob}(\mathrm{PAR}=1)$ & & $\begin{array}{c}0.720 \\
(0.655)(0.775)\end{array}$ \\
\hline LR Statistic & $87.379 * * *$ & $72.153^{* * *}$ \\
\hline
\end{tabular}

Notes: See table 1 for a detailed description of the variables. Column 2 presents asymptotic standard errors in parentheses except for Mean PAY*, for which (parametric) asymptotic confidence intervals are presented. Column 3 presents bootstrapped $95 \%$ confidence intervals in parentheses

* Significant at a $10 \%$ level $* *$ Significant at a $5 \%$ level $\quad * * *$ Significant at a $1 \%$ level 
Table 4. Within-Sample Prediction Performance for Willingness to Pay

\begin{tabular}{l|ccccccc}
\hline \hline & \multicolumn{7}{c}{ PREDICTED } \\
\hline & & $(-\infty, 1.00)$ & {$[1.00,1.50)$} & {$[1.50,2.00)$} & {$[2.00,2.50)$} & {$[2.50, \infty)$} & Total \\
$\mathrm{A}$ & $(-\infty, 1.00)$ & 1 & 14 & 18 & 6 & 2 & 41 \\
$\mathrm{C}$ & {$[1.00,1.50)$} & 1 & 11 & 29 & 11 & 1 & 53 \\
$\mathrm{~T}$ & {$[1.50,2.00)$} & 0 & 7 & 18 & 33 & 5 & 63 \\
$\mathrm{U}$ & {$[2.00,2.50)$} & 0 & 7 & 23 & 30 & 13 & 73 \\
$\mathrm{~A}$ & {$[2.50, \infty)$} & 0 & 4 & 18 & 46 & 37 & 105 \\
$\mathrm{~L}$ & Total & 2 & 43 & 106 & 126 & 58 & 335 \\
\hline
\end{tabular}

Table 5. Within-Sample Prediction Performance for Willingness to Participate

\begin{tabular}{l|cccc}
\hline \hline & \multicolumn{4}{|c}{ PREDICTED } \\
\hline A & & Participate & Do Not Participate & Total \\
C & Participate & 203 & 26 & 229 \\
T & Po & 40 & 106 \\
U & Do Not Participate & 66 & 66 & 335 \\
A & Total & 269 & & \\
L & & & & \\
\hline
\end{tabular}




\section{References}

Abdelmoneim, Elnagheeb H. and Jeffrey L. Jordan. (1995) "Comparing Three Approaches That Generate Bids for the Referendum Contingent Valuation Method," Journal of Environmental Economics and Management, 29, 92-104.

Alberini, Anna. (1995a) "Testing Willingness-to-Pay Models of Discrete Choice Contingent Valuation Survey Data,” Land Economics, 71(1), 83-95.

Alberini, Anna. (1995b) "Efficiency vs. Bias of Willingness-to-Pay Estimates: Bivariate and Interval Data Models," Journal of Environmental Economics and Management, 29, 169180.

Allen, Frank Edward. (1992) "As Recycling Surges, Market for Materials is Slow to Develop," Wall Street Journal, January 17, A1.

Amemiya, Takeshi. (1981) "Qualitative Response Models: A Survey,” Journal of Economic Literature, 19, 1483-1536.

Arrow, Kenneth, Robert Solow, Paul R. Portney, Edward E. Leamer, Roy Radner, and Howard Schuman. (1993) "Report of the NOAA Panel on Contingent Valuation," Federal Register, 58(10), 4601-4614.

Bailey, Jeff. (1992) “Economics of Trash Shift as Cities Learn Dumps Aren't So Full,” Wall Street Journal, June 2, A1.

Bergstrom, John C., John R. Stoll, and Alan Randall. (1990) "The Impact of Information on Environmental Commodity Valuation Decisions," American Journal of Agricultural Economics, August, 614-621.

Bohm, Peter. (1979) "Estimating Willingness to Pay: Why and How?," Scandinavian Journal of Economics, 142-153.

Brookshire, David S., Mark A. Thayer, William D. Schulze, and Ralph C. D’Arge. (1982) "Valuing Public Goods: A Comparison of Survey and Hedonic Approaches," The American Economic Review, 72(1), 165-177.

Cameron, Trudy Ann. (1988) “A New Paradigm for Valuing Non-market Goods Using Referendum Data: Maximum Likelihood Estimation by Censored Logistic Regression," Journal of Environmental Economics and Management, 15, 355-379.

Cameron, Trudy Ann and Michelle D. James. (1987) "Efficient Estimation Methods for 'CloseEnded' Contingent Valuation Surveys," The Review of Economics and Statistics, 69, 269276. 
Carson, Richard T., W. Michael Hanemann, Raymond J. Kopp, Jon A. Krosnick, Robert C. Mitchell, Stanley Presser, Paul A. Ruud, and V. Kerry Smith, with Michael Conaway and Kerry Smith. (1996) "Temporal Reliability of Estimates From Contingent Valuation." Unpublished manuscript, Department of Economics, University of California, San Diego.

Cummings, Ronald G., David S. Brookshire, and William D. Schulze, eds. (1986) Valuing Environmental Goods: A State of the Arts Assessment of the Contingent Valuation Method. Rowman and Allanheld.

Dan Jones \& Associates. (1997) Ogden City Waste Management Survey.

Davidson, Russel and James G. MacKinnon. (1993) Estimation and Inference in Econometrics. Oxford University Press, New York and Oxford.

Diamond, Peter A. and Jerry A. Hausman. (1994) "Contingent Valuation: Is Some Number Better Than None?," Journal of Economic Perspectives, 8(4), 45-64.

Environmental Protection Agency. (1998) Pay-As-You-Throw Communities. http://www.epa.gov/payt/states/contacts.htm\#mn.

Franklin, William E. and Marjorie A. Franklin. (1992) "Putting the Crusade into Perspective," EPA Journal, 18(3), 7-14.

Fullerton, Don and Thomas C. Kinnaman. (1996) "Household Responses to Pricing Garbage by the Bag," American Economic Review, 86(4), 971-984.

Glenn, Jim. (1998) “The State of Garbage in America,” BioCycle, 39(4), 32-43.

Goodstein, Eban. (1998) Economics and the Environment, 2nd Edition. Prentice Hall.

Greene, William H. (1993) Econometric Analysis, $3^{\text {rd }}$ Edition. Prentice Hall.

Hanemann, Michael W. (1984) "Welfare Evaluations in Contingent Valuation Experiments with Discrete Responses," American Journal of Agricultural Economics, August, 332-341.

Hausman, Jerry A. (1993) Contingent Valuation: A Critical Assessment. North Holland.

Holmes, Thomas P. and Randall A. Kramer. (1995) “An Independent Sample Test of Yea-Saying and Starting Point Bias in Dichotomous-Choice Contingent Valuation," Journal of Environmental Economics and Management, 29, 105-121.

Hong, Seonghoon, Richard M. Adams, and H. Alan Love. (1993) "An Economic Analysis of Household Recycling of Solid Wastes: The Case of Portland Oregon," Journal of 
Environmental Economics and Management, 25, 136-146.

Hopper, Joseph R. and Joyce M. Nielson. (1991) "Recycling as Altruistic Behavior, Normative and Behavioral Strategies to Expand Participation in a Community Recycling Program," Environment and Behavior, 23(2), 195-220.

Horowitz, John K. and Kenneth E. McConnell. (1998) “A Review of WTA/WTP Studies.” Unpublished manuscript.

Jackus, Paul M., Kelly H. Tiller, and William M. Park. (1996) "Generation of Recyclables by Rural Households," Agricultural and Resource Economics, 21, 96-108.

Kanninen, Barbara J. (1995) "Bias in Discrete Response Contingent Valuation," Journal of Environmental Economics and Management, 28, 114-125.

Kinnaman, Thomas C. (1998) "The Efficiency of Solid Waste Recycling: A Benefit-Cost Analysis," Unpublished manuscript. Bucknell University Department of Economics.

Kealy, Mary Jo, Mark Montgomery, and John F. Dovidio. (1990) "Reliability and Predictive Validity of Contingent Values: Does the Nature of the Good Matter?," Journal of Environmental Economics and Management, 19, 244-263.

Lake, Iain R., Ian J. Bateman, and Julian P. Parfitt. (1996) "Assessing a Kerbside Recycling Scheme: A Quantitative and Willingness to Pay Case Study," Journal of Environmental Management, 46, 239-254.

Lee, L. F. (1976) "Estimation of Limited Dependent Variable Models by Two-Stage Methods," $\mathrm{Ph} . \mathrm{D}$. dissertation, University of Rochester.

Loomis, John B. (1990) "Comparative Reliability of the Dichotomous Choice and Open-Ended Contingent Valuation Techniques," Journal of Environmental Economics and Management, 18, 78-85.

Maddala, G. S. (1983) Limited-Dependent and Qualitative Variables in Econometrics. Cambridge University Press.

McConnell K. E. (1990) "Models for Referendum Data: The Structure of Discrete Choice Models for Contingent Valuation," Journal of Environmental Economics and Management, 18, 19-34.

Mitchell, Robert C. and Richard T. Carson. (1989) Using Surveys to Value Public Goods: The Contingent Valuation Method. Resources for the Future. 
Morris, G.E., and D.M. Holthausen. (1994) "The Economics of Household Solid Waste Generation and Disposal," Journal of Environmental Economics and Management, 26, 215-234.

Ogden City Community Development. (1998) Ogden City Profile, 1997.

Ogden City Public Works Department. (1998) Ogden Refuse Collection Rate History.

Oskamp, Stuart, Maura J. Harrington, Todd C. Edwards, Deborah L. Sherwood, Shawn M. Okuda, and Deborah C. Swanson. (1991) "Factors Influencing Household Recycling Behavior," Environment and Behavior, 23(4), 494-519.

Sagoff, Mark. (1988) The Economy of the Earth. Cambridge University Press.

SCS Engineers. (1996) Weber County Waste Reduction/Recycling Plan.

Stock, Wendy. (1997) "Willingness to Pay for Curbside Recycling: A Contingent Valuation and Empirical Analysis," Unpublished Manuscript. Kansas State University, Department of Economics.

Tietenberg, Tom. (1998) Environmental Economics and Policy, 2nd Edition. Addison Wesley.

Tiller, Kelly H., Paul M. Jakus, and William M. Park. (1997) "Household Willingness to Pay for Dropoff Recycling," Journal of Agricultural and Resource Economics, 22(2), 310-320.

Vining, Joanne and Angela Ebreo. (1990) "What Makes a Recycler? A Comparison of Recyclers and Nonrecyclers," Environment and Behavior, 22(1), 55-72.

Whitehead, John C. (1995) "Willingness to Pay for Quality Improvements: Comparative Statics and Interpretation of Contingent Valuation Results," Land Economics, 71(2), 207-215. 


\section{Endnotes}

${ }^{1}$ In some areas of the country landfill space has actually increased, working to decrease tipping fees. In some of these areas, however, the increased space may partially be a result of recycling (Bailey, 1992). For more information on management of municipal solid waste see Tietenberg (1998), Goodstein (1998), Franklin and Franklin (1992), Sagoff (1988), and Glenn (1998).

${ }^{2}$ An estimated 9,000 communities in the U.S. currently have curbside recycling programs (Glenn, 1998). The U.S. Environmental Protection Agency (EPA) estimates that several of these communities also have in place "Pay-As-You-Throw" variable rate structures (EPA, 1998). It therefore seems likely that many of these communities surveyed their residents' willingness to participate and pay as part of their information-gathering processes.

${ }^{3}$ The city of Ogden is located approximately 40 miles north of Salt Lake City in west central Utah. According to recent estimates its population is approximately 68,000 (Ogden City Community Development Office, 1998).

${ }^{4}$ Until its closure, the Weber County Landfill serviced 165,000 county residents, accepting approximately 180,000 tons per year of solid waste (SCS Engineers, 1996). This tonnage represented an average annual increase in the quantity of disposed solid waste since 1991 of approximately 4.4 percent (Ibid). From 1990 to 1996 the county tipping fee had risen an average of approximately 21 percent per year, translating into an average annual increase in monthly household rates of approximately 7 percent (Ogden City Public Works, 1998).

${ }^{5}$ Except for an aborted attempt at privatized curbside recycling collection in 1992, Ogden has never offered any form of curbside collection of recyclable materials (Stock, 1997). Few centralized recycling options are presently available in the local area.

${ }^{6}$ Several recent studies have examined the issue of expanding recycling services in cities which presently have curbside recycling programs. These include Fullerton and Kinnaman (1996), Kinnaman (1996), Lake et al. (1996), Hong et al. (1993), Hopper and Nielsen (1991), and Vining and Ebreo (1990). Tiller, et al. (1997) consider the issue of centralized drop-off recycling programs in rural and suburban areas of Tennessee. Aside from Stock (1997), we know of no other studies which have examined the value that households place on curbside recycling in cities which do not presently have such a program in place.

${ }^{7}$ Cummings et al. (1986) and Mitchell and Carson (1989) argue in favor of this possibility. Bergstom et al. (1990) contend that the more "service information" a respondent has available, the more complete and accurate is his valuation of non-use goods. Alternatively, using an experimental setting, Kealy et al. (1990) find no support for the thesis that the nature of a good determines the reliability and predictive validity of the $\mathrm{CV}$ method.

${ }^{8}$ Mitchell and Carson (1989), Cummings et al. (1986), and Hausman (1993) provide good overviews of the reliability and validity problems associated with the $\mathrm{CV}$ method. For research 
specific to dichotomous-choice formats, see Loomis (1990), Alberini (1995a), Alberini (1995b), Kanninen (1995), Brookshire et al. (1982), Abdelmoneim and Jordan (1995), and Holmes and Kramer (1995). This literature also encompasses research which has attempted to develop a cohesive theoretical framework within which standard estimation techniques, such as probit and logit analysis, can be used to estimate various welfare measures. See Hanemann (1984) and Cameron (1988) for two seminal perspectives on the need for grounding CV analysis in a utilitytheoretic framework.

${ }^{9}$ The NOAA panel's survey guidelines are generally well-respected by practitioners of CV analysis. See Carson, et al. (1996) for further discussion.

${ }^{10}$ As a premise to the willingness-to-pay question, respondents were asked, "In addition to your current monthly bill....." This type of question therefore grounds their responses in prior experience. Similar premising was provided throughout the survey were appropriate. The final version of the survey instrument was pre-tested on 20 individuals. The instrument was also pretested during the various stages of a standard revision process (personal communication with Dan Jones \& Associates).

${ }^{11}$ According to Arrow et al. (1993, p. 4608), "A CV survey does not have to meet each of these guidelines fully in order to qualify as a source of reliable information...Many departures from the guidelines or even a single serious deviation would, however, suggest unreliability prima facie."

${ }^{12}$ By "conservative" we mean that the intervals are not extremely wide and therefore do not extend to explicitly large values. In this way we diminish what is commonly known as high-end "anchoring bias." Although any choice of intervals is open to some anchoring bias, this bias is less likely to affect estimates of the marginal effects than that of mean willingness to pay. It is important to note that the intervals chosen for this survey encompass the more common monthly rates that presently exist throughout the U.S. (Resource Recycling, recent issues).

${ }^{13}$ The survey non-response rate was approximately 29 percent of all telephone calls made. Dan Jones and Associates believes that this resulted from the length of the survey (each respondent was advised of the survey's expected length, which was 20 minutes). The survey's length was due to the fact that the 85 questions covered more services than just curbside recycling (additional services included drop-off recycling, green-waste recycling, Spring cleanup, and Christmas-tree removal). Thus, it is unclear whether or not this survey suffers from nonresponse bias, as it could be that as many pro-recyclers were deterred from participating (due to the survey's length) as were con-recyclers (due to their distastes for recycling).

${ }^{14}$ The superscripted ${ }^{*}$ denotes that these values are unobservable to the researcher.

${ }^{15}$ In willingness-to-pay studies, $\mathrm{PAY} *$ is often measured in natural logarithms because negative willingness to pay is not allowed. However, one can argue that within the context of curbside recycling some individuals may not be willing to participate in a curbside recycling program 
unless they are paid. This is due to the costs involved in generating recyclable materials (Jackus et al., 1996), or to the lost income associated with recycling items such as aluminum cans and newspapers. Moreover, in Stock's (1997) survey of Ogden residents, several of the respondents explicitly mentioned having a negative willingness to pay for curbside recycling.

${ }^{16}$ This model therefore allows households to simultaneously have positive PAY* values, but be unwilling to participate $\left(\mathrm{PAR}^{*}<0\right)$. This could occur, for instance, when a household desires that the service be made available for others, even though it would not consider participating itself. Alternatively, an individual may simply expect the monthly fee to exceed their monthly willingness to pay. A total of four households in our survey responded with a positive willingness to pay, but an unwillingness to participate in a curbside recycling program.

${ }^{17}$ Maddala (1983) describes a recursive simultaneous qualitative-response system as one in which the action taken with $\mathrm{y}_{1}$ precede the action taken with $\mathrm{y}_{2}$. In our model, however, it is the intentions about $\mathrm{y}_{1}$ (i.e., $\mathrm{PAY}^{*}$ ) that precede the intentions about $\mathrm{y}_{2}$ (i.e., $\mathrm{PAR}^{*}$ ). In this sense, our description of the system as recursive is more in line with the traditional definition of a recursive or triangular system; see Greene (1993, pp. 736-737).

${ }^{18}$ See Lee (1976) and Maddala (1983) for more details on two-stage estimation in qualitative dependent variable models.

${ }^{19}$ Another commonly specified distribution for $\mathrm{F}$ is the logistic distribution. The standard normal and logistic densities are similar in shape except for the fatter tails in the latter distribution. As a consequence, unless the sample is substantially unbalanced or there is wide variation in the independent variables, the choice between the distributions is unlikely to affect the results in any meaningful manner; see Amemiya (1981, pp. 1487-1489) and Green (1993, pp. 875-876). We estimated the models using both the logistic and standard normal distributions and found them to be remarkably similar. We therefore reproduce the results from only the standard normal distribution given its prominence in statistical analysis.

${ }^{20}$ Notice that identification of the elements in $\boldsymbol{\theta}_{1}$ is not required to estimate the probabilities of falling within a particular willingness-to-pay interval and the corresponding marginal effects.

${ }^{21}$ The results in Tables 3, 4 and 5 appear to be robust to omitting observations associated with item non-response. Rather than deleting the 66 item non-response observations, we also lumped these observations into the "omitted" category for the independent variables and dependent variables. We found the results to be qualitatively similar in the two cases.

${ }^{22}$ The chi-squared statistic for the null hypothesis that the slope coefficients in (1) are jointly zero is 87.379 , which allows us to reject the null at the $1 \%$ level.

${ }^{23}$ Presently in Ogden, one private recycling company pays for newspapers and aluminum. 
${ }^{24}$ Notice that the estimated coefficient on High Income, while positive, is not statistically significant. We offer a couple of possible reasons for this counterintuitive result. One, it could simply be a sample phenomenon. After all, at a 90\% confidence level, you would expect at least one of the coefficients to show up as statistically insignificant even if they were all known to be different than zero in actuality. And two, it may be that data set is not rich enough to accurately distinguish the effects of those with income levels between $\$ 30 \mathrm{~K}$ and $\$ 50 \mathrm{~K}$ from those with income levels over $\$ 50 \mathrm{~K}$. It should be noted, however, when all those with incomes above $\$ 30 \mathrm{~K}$ are lumped together into High Income, the results indicate that they are willing to pay 17 cents more than those with incomes less than $\$ 30 \mathrm{~K}$ and the result is significant at the $90 \%$ confidence level.

${ }^{25}$ Recall, Middle Income and Young are included to capture each individual's expectation of the curbside recycling fee, which appears in (2) with a negative coefficient. Therefore, the negative signs indicate that young individuals with average incomes, all else equal, expect higher fees to be charged for curbside recycling.

${ }^{26}$ This is of course only true for small changes in the predicted value of PAY evaluated at the sample mean of all other explanatory variables. For instance, it does not imply that a $\$ 2.00$ increase in PAY will increase the probability of participation by a nonsensical 152 percentage points.

${ }^{27}$ Similar to Hong, et al. (1993), Hopper and Nielsen (1991), and Oskamp, et al. (1991), Jakus, et al. (1997) find that several demographic variables influence a rural household's probability of participating in a drop-off recycling program. In addition, they find that household production constraints determine participation. Jakus, et al. also do not control for the simultaneous nature of the household's decision-making process.

${ }^{28}$ Our mean and median willingness-to-pay values are larger than the lower bound of approximately $\$ 0.86$ estimated by Kinnaman (1998) for his sample from Lewisberg, Pennsylvania.

${ }^{29}$ This result is similar to Kinnaman (1998), who estimates a 75-percent participation rate. None of the other studies which measure participation (Jakus, et al. (1997), Hong, et al. (1993), and Fullerton and Kinnaman (1996)) report mean probability estimates.

${ }^{30}$ The following break-even analysis is based on information provided by Dan Grigsby, Operations Manager, Ogden City Public Works Department.

${ }^{31}$ Based on Ogden's earlier, ill-fated experience with voluntary curbside recycling (see Stock (1997) for more details), the city's Public Works officials have decided that any future municipal curbside program will be mandatory (at least during its initial years). Furthermore, it is difficult to estimate break-even fees under voluntary participation, as participation and the monthly fee are mutually dependent on one another. Voluntary participation implies a higher break-even fee, 
which in turn implies lower participation. Thus, a break-even fee is difficult to pin down ex ante for a voluntary program.

32 The initial customer base for this analysis is assumed to be 18,887 households in 1999 , with an expected growth rate of 1 percent per year. Further, for the purposes of this analysis, it is assumed that no revenue will be generated by the sale of RSW. Bonding interest expenses for new trucks, carts, and the construction of an integrated processing facility are included in the calculations for the split-cart option. 